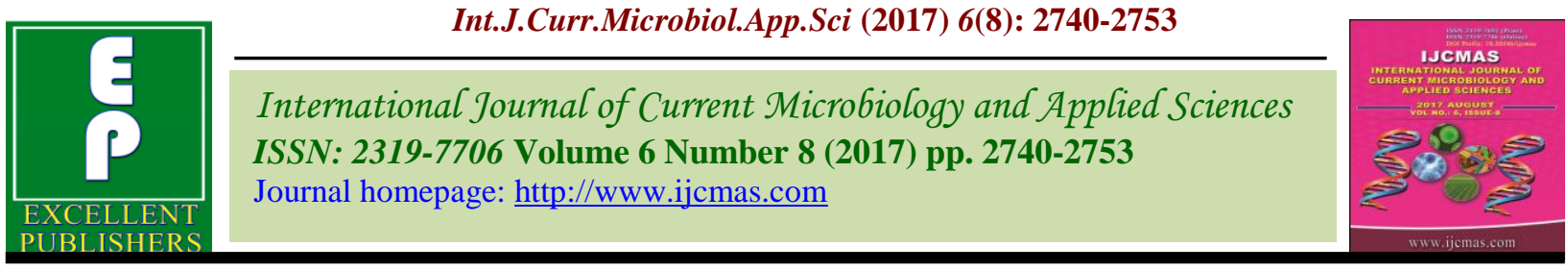

Original Research Article

https://doi.org/10.20546/ijcmas.2017.608.328

\title{
Biomass Yield Efficiency of Baker's Yeast Strain on Agro-Industrial Wastes and Its Utilization in Bread Making
}

\author{
Hiranmay Malik, Priya Katyal" and Savita Sharma \\ College of Basic Sciences and Humanities, Punjab Agricultural University, \\ Ludhiana- 141004, Punjab, India \\ *Corresponding author
}

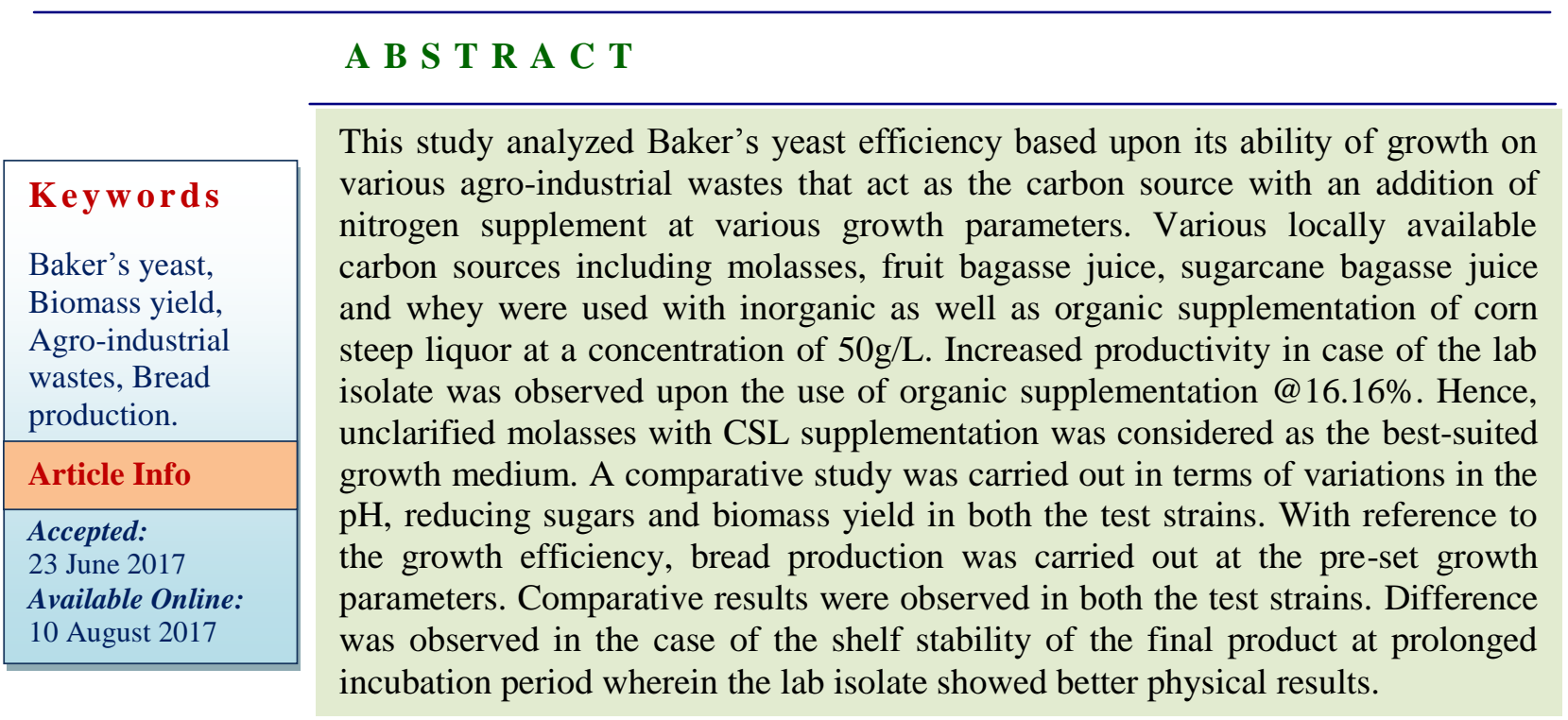

\section{Introduction}

Fermentation is any process involving the mass culture of microorganisms, either aerobically or anaerobically [1]. It is also the use of an organic substrate as the electron donor and a degraded organic substrate as an electron acceptor. Saccharomyces cerevisiae, also known as the Baker's yeast, has been used in the fermentation industry for long, as a basic tool for fermentation of the dough. Manufacturers of baker's yeast are in constant pursuit of strains with improved dough-rising properties and capacity to retain fermentative ability during storage at a low temperature in order to meet baking industry requirements such as the increasing use of frozen dough's
[2]. the function of yeast in bread making which is considered as a staple food for a large section of world's population) cannot be successfully replaced by any other ingredient, thus, it is vital for the baking trade [3].

The concept of utilizing excess biomass or wastes from agricultural and agro-industrial residues to produce energy, feeds or foods, and other useful products is not necessarily new. Recently, fermentation of biomass has gained considerable attention due to the forthcoming scarcity of fossil fuels, and also due to the necessity of increasing world food and feed supplies [4]. The objective of 
baker's yeast manufacturing is to harvest as fast as possible the highest amount of living cell mass at the lowest cost without any due wastage. Therefore, the demand to optimize the yield on best-suited carbon and nitrogen source is being practiced.

The different parameters for the analysis of various commercial yeasts and an isolate from fermenting orange juice include: physicochemical analysis, biochemical analysis, fermentation and assimilation studies, pseudohyphae formation, carbohydrate and trehalose content, invertase activity and freeze tolerance ability. The microbiological analysis revealed a contrasting behavior among various yeasts preparations 5 .

The rationale of the present study, depending on these parameters was to select the most efficient yeast strain among the various commercial yeasts and to compare its efficiency against the lab isolate.

Allinson yeast was selected for comparison with the fruit juice isolate for growth study analysis on various carbon and nitrogen sources, and further, for the production of bread as a final product.

Allinson yeast showed maximum carbohydrate content (33.62\%) among the commercial strains, which was comparable with FJ1 (33.89\%). Trehalose content was maximum in FJ1 followed by Falora $(3.38 \%)$. However, invertase activity of Allinson was found highest $(205 \mathrm{U} / \mathrm{mg})$. On the basis of highest freeze tolerance, high invertase activity, high carbohydrate content, comparable trehalose content and highest dough rising ability, Allinson yeast was selected as a control against the lab isolate whose morphological and biochemical characterization depicts a variation from the selected commercial yeasts [5].

\section{Materials and Methods}

Standardization of parameters for optimum biomass production

\section{Effect of pH on biomass production}

The growth of both the selected isolates was studied in a buffered medium (GYE) with $\mathrm{pH}$ values of 4.0, 4.5, 5.0, 5.5, 6.0 and 6.5 at 100 RPM and a temperature of $28^{\circ} \mathrm{C}$. Optical density was measured at $580 \mathrm{~nm}$ up to $54 \mathrm{hrs}$.

\section{Effect of temperature on biomass production}

Shaking the incubator at 100 RPM, the effect of temperature on growth of both the isolates was studied at the optimized $\mathrm{pH}$ at $20^{\circ} \mathrm{C}$, $25^{\circ} \mathrm{C}, 30^{\circ} \mathrm{C}, 35^{\circ} \mathrm{C}$ and $40^{\circ} \mathrm{C}$.

\section{Effect of aeration on biomass production}

Similarly, the growth of both the strains was studied in a buffered medium (GYE) with an optimized $\mathrm{pH}$ and incubated at a different rotation per minute (RPM) i.e. $80,100,120$, 140.

\section{Different agro-industrial sources as substrate for biomass production}

The growth of selected isolates at optimized conditions was studied by using five different agro-industrial wastes i.e. Molasses (Clarified), Molasses (Un-clarified), Fruit bagasse juice, Whey and Sugar cane bagasse juice.

\section{Molasses (Clarified) as substrate for biomass production}

Sugarcane molasses of $86.7 \%$ total sugar and pH 6.4 was obtained from The Budhewal Cooperative Sugar Mill Ltd., Ludhiana. Molasses clarification, according to the 
method given by [3], was done. For growth analysis in clarified medium, preparation of 1 litre (10\% sugar), that included $400 \mathrm{ml}$ of clarified molasses $(25 \%)$ sugar, was added to $600 \mathrm{ml}$ of tap water with $1.5 \mathrm{~g}$ of urea, $0.5 \mathrm{~g}$ of $\mathrm{KH}_{2} \mathrm{PO}_{4}$ and $0.5 \mathrm{~g}$ of $\mathrm{MgSO}_{4}$. Periodic samples were collected at $6 \mathrm{hr}$ intervals for biomass yield and an optical density was noted at $600 \mathrm{~nm}$.

Molasses (un-clarified) as substrate for biomass production

Growth analysis was also done in an unclarified molasses medium, where the clarification step was not performed. Supplementation was done similar to the above case.

\section{Whey as substrate for biomass production}

Whey was collected from a local dairy and stored under refrigeration conditions. Medium for the biomass production of baker's yeast was prepared [6]. This included: Whey: 50ml, Yeast Extract: $3.0 \mathrm{~g}, \quad\left(\mathrm{NH}_{4}\right)_{2} \mathrm{HPO}_{4}: \quad 1.0$, $\left(\mathrm{NH}_{4}\right)_{2} \mathrm{SO}_{4}: 2.0, \mathrm{MgSO}_{4}: 0.5$ per litre of water.

\section{Sugarcane juice extracted from sugarcane bagasse for biomass production}

Sugarcane bagasse was procured from the local market and was grounded to a fine particle size. The wet method [7] was performed using $0.2 \mathrm{~g} \mathrm{NaOH}$ per g bagasse pith, with a solid: liquid ratio of 1: 10 .

\section{Fruit Juice extracted from fruit bagasse as substrate for biomass production}

The method given by [8] was followed. Freshly processed fruit waste was collected from a fruit juice vendor and shredded to a small particle size. Tap water was added in the ratio of $1: 1$ by weight. The solid residue was separated from liquid fraction by centrifugation at $4000 \mathrm{RPM}$ for $5 \mathrm{~min}$; the supernatant was, thus, used for yeast cultivation. Inorganic supplementation was done by addition of $\mathrm{NH}_{4} \mathrm{H}_{2} \mathrm{PO}_{4} @ 5 \mathrm{~g} / \mathrm{L}$.

\section{Supplementation of nitrogen source}

Since un-clarified molasses was considered as the best carbon source, organic nitrogen supplementation was done with corn steep liquor (CSL) as an alternative source of nitrogen that was supplemented @ 50g/L.

\section{Biomass production studies at optimized conditions}

Molasses supplemented with corn steep liquor at a concentration of $50 \mathrm{~g} / \mathrm{L}$ was used for the biomass production of baker's yeast. A quantity of 5L was prepared for the biomass production. Further, periodic samples were drawn for $\mathrm{pH}$, reducing sugar and biomass estimation of the yeast up to $54 \mathrm{hrs}$. The biomass concentrate for each yeast sample was obtained by centrifugation at 6000 RPM for $15 \mathrm{~min}$. The concentrate was washed sufficiently with sterilized water and was stored under refrigeration for bread making.

\section{Physicochemical properties of raw materials and final product}

Wheat flour procured from the market was analyzed for their moisture content, crude protein, Ash, Fat and Gluten as per the standard methods [9]. The final product (Bread) prepared from commercial yeast and theFJ1 isolate was analyzed for the same parameters.

\section{Baking properties}

\section{Quality analysis of final product}

After supplementing a considerable amount of biomass production from molasses with corn steep liquor, it was used in the preparation of 
bread. Straight dough AACC method, with remixing procedures [10], was followed with a difference that dough was mixed using the desired water absorption.

\section{Bread quality}

The loaves were packed in polyethylene bags and analyzed for loaf weight, crumb characteristics and crust characteristics. The volume of the bread was noted by the rapeseed displacement method [11].

\section{Evaluation of sensory attributes of bread prepared from commercial yeast and FJ1}

The bread was evaluated organoleptically on the basis of appearance, color, texture, flavor and overall acceptability by a panel of judges. Consumer acceptance of the products was evaluated on a nine-point "Hedonic scale".

Shelf stability of bread fermented by selected commercial yeast and FJ1 isolate

Shelf stability of both the bread loaves was carried out for an incubation period of 1 month at a room temperature. Thereafter, physical appearance for any fungal contamination was noted.

\section{Results and Discussion}

\section{Effect of pH on biomass production}

Results presented in figures 1 and 2 revealed a $\mathrm{pH}$ of 6.0 as best for cell biomass production in the commercial yeast strain as well as in FJ1 isolate. While at 4.5 and 5.0, $\mathrm{pH}$ minimum growth was observed. The study reported maximum production rate (sugar consumption and dry cell mass) of $S$. cerevisiaeisolated from dates (predominant in Pakistan) at the initial $\mathrm{pH}$ of 6 [12]. These little differences can be due to the isolates origin, where the strains under the present investigation were isolated from commercial yeasts preparation produced from controlled fermentation processes in the fermenters which adapted over the time to low $\mathrm{pH}$ and also from natural processes in fermenting juice.

\section{Effect of temperature on biomass production}

Results presented in figures 3 and 4 showed an optimum cell growth at $30^{\circ} \mathrm{C}$, whereas, comparatively lesser growth were recorded at $35^{\circ} \mathrm{C}$ and $40^{\circ} \mathrm{C}$. Least growth was recorded at a temperature of $20^{\circ} \mathrm{C}$ and $25^{\circ} \mathrm{C}$.

In this regard, the study conducted showed the changes in growth, expressed as a dry weight of $S$. cerevisiae, after $24 \mathrm{~h}$ of incubation, over a temperature range of 20$40^{\circ} \mathrm{C}$ [13]. Whereby, growth on both substrates i.e. glucose syrup and molasses was significantly affected by the incubation temperature.

\section{Effect of aeration on biomass production}

The yeast cell has the valuable characteristic of being able to grow in varied environments. The presence of oxygen is clearly a necessary condition for aerobic metabolism [14].

Therefore, the growth of baker's yeast at different aeration rates was checked. Results showed that maximum growth of yeast was observed at 120 RPM (Figures 5 and 6).

Further, increase in aeration to 140 RPM did not result in any significant increase in the biomass production of yeast.

Allinson yeast showed minimum growth at both the extremes of RPM (80 and 140), but FJ1 isolate showed the least growth at 80 RPM whereas, at 100 and 140 RPM no significant difference in growth was observed. 


\section{Different agro-industrial sources as} substrate for biomass production

The growth of baker's yeast was studied on five different agro-industrial wastes that included molasses (clarified), molasses (unclarified), whey, sugarcane bagasse juice and fruit bagasse juice. Growth was measured in terms of increase in optical density (600nm) periodically at $6 \mathrm{hr}$ internal up to $54 \mathrm{hrs}$. Biochemical composition of thedifferent substrate is given in table 1.

Many studies reported that sugarcane molasses can be used as a substrate for the production of yeast biomass [15]. Commercial yeast, as well as the FJ1 isolate grown on clarified molasses, showed extensive growth at the optimized conditions, thereby, depicting the usefulness of molasses as a rich carbon source.

The preliminary study conducted to test the potential of the molasses, in supporting the growth of yeast cells, indicated that both the yeast strains were able to grow by assimilating the sugar present in molasses, regardless of the initial sugar concentration. Allinson showed a maximum biomass production of $0.524 \mathrm{~g} / 100 \mathrm{ml}$ at an optical density of 0.655 after $42 \mathrm{hr}$ of incubation, whereas, FJ1 isolate showed maximum biomass yield of $0.544 \mathrm{~g} / 100 \mathrm{ml}$ at an optical density of 0.890 after $42 \mathrm{hr}$ of incubation.

These results are in accordance with the results obtained [3], who observed that a medium of molasses (10\% sugar) after $24 \mathrm{hr}$ seemed to be an efficient substrate.

Moreover, a study reported the good sugar utilization with an initial sugar concentration up to $10 \%(\mathrm{w} / \mathrm{v})$; however, the utilization decreased significantly, when its concentration was increased from 15 to $20 \%$ [16].
Molasses (un-clarified) as substrate for biomass production

Commercial yeast and FJ1 isolate grown on un-clarified molasses, as the sole carbon source, showed maximum growth in terms of the optical density measured at $600 \mathrm{~nm}$. Figures 7 and 8 show the comparative increase in optical density $(600 \mathrm{~nm})$ of both Allinson and FJ1 isolate on different agroindustrial substrates, which depicts the maximum growth of both the yeast strains that are grown on an un-clarified molasses medium supplemented with inorganic elements. Maximum biomass yield of 0.577 $\mathrm{g} / 100 \mathrm{ml}$ at an optical density of 0.777 after 48 hr of incubation was observed in commercial yeast, whereas FJ1 isolate exhibited maximum yield of 0.597 at an optical density of 0.988 after $36 \mathrm{hr}$ of incubation. In this regard, a study illustrated the good utilization of sugar obtained with initial sugar concentration up to $10 \%(\mathrm{w} / \mathrm{v})$, however, the utilization decreased significantly when the concentration was increased from 15-20\% [3]. They added that the decreased utilization with high concentrations was probably due to osmotic effects on yeast cell membrane (Figs. 9 and 10).

\section{Whey as substrate for biomass production}

Whey, a valuable product from cheese manufacturing units, was obtained from a local dairy. Whey contains basic sugar lactose and also contains vitamins, minerals which improve the physiological activity of yeast cells. To achieve a good utilization of lactose from whey, it is especially important to choose a yeast strain with suitable physiological characteristics. The growth of commercial yeast and FJ1 isolate on whey showed a significantly lower growth in comparison to molasses medium. Allinson exhibited maximum biomass yield of 0.312 $\mathrm{g} / 100 \mathrm{ml}$ at an optical density of 0.388 after 36 
hr of incubation, whereas FJ1 isolate showed a maximum yield of $0.323 \mathrm{~g} / 100 \mathrm{ml}$ at an optical density of 0.477 after $36 \mathrm{hr}$ of incubation. This may be, as lactose is not a preferred sugar for utilization by the selected yeast.

Sugarcane bagasse juice as substrate for biomass production

Sugarcane bagasse juice procured from the local market, which was processed by the wet method [7], was used for the growth study of baker's yeast. It showed limited growth as compared to molasses (both un-clarified and clarified). Growth was significantly lower than the growth in molasses.

Allinson yeast showed maximum biomass yield of $0.476 \mathrm{~g} / 100 \mathrm{ml}$ at an optical density of 0.587 after $48 \mathrm{hr}$ of incubation, whereas, FJ1 isolate showed maximum growth yield of $0.480 \mathrm{~g} / 100 \mathrm{ml}$ at an optical density of 0.754 after $42 \mathrm{hr}$ of incubation. Sugarcane bagasse juice showed a limited growth in comparison to the molasses medium though it was higher than that exhibited by whey as the substrate.

\section{Fruit bagasse as substrate for biomass production}

Fruit bagasse was collected from a local fruit juice vendor and the juice was extracted by boiling $1 \mathrm{Kg}$ of bagasse in 1 litre of tap water. This substrate supported minimum growth as a measure of optical density at $600 \mathrm{~nm}$.

Allinson yeast showed maximum biomass yield of $0.279 \mathrm{~g} / 100 \mathrm{ml}$ at an optical density of 0.278 after $48 \mathrm{hr}$ of incubation, whereas FJ1 isolate showed a maximum yield of 0.268 $\mathrm{g} / 100 \mathrm{ml}$ at an optical density of 0.222 after 42 $\mathrm{hr}$ of incubation. Fruit bagasse juice showed least growth yield, in the case of the commercial as well as the isolated yeast, and was considered the least preferred source for yeast biomass production.

\section{Supplementation of nitrogen source}

For increasing the biomass production and replacement of molasses with another industrial waste, corn steep liquor (CSL), which is another industrial waste from maize processing industry and is rich in nitrogen, has been used as an organic supplement for nitrogen.

The comparatively higher optical density of commercial yeast with molasses + CSL as a growth medium, in comparison to molasses (un-clarified) alone, showed its applicability as being a better and cheaper source of nitrogen.

Organic supplementation of un-clarified molasses with CSL @ 50g/L resulted in improved biomass yield, with a significantly higher biomass production of $0.589 \mathrm{~g} / 100 \mathrm{ml}$ at an optical density of 0.798 in case of Allinson yeast, whereas it was $0.612 \mathrm{~g} / 100 \mathrm{ml}$ at an optical density of 0.994 after $48 \mathrm{hr}$ of incubation, as compared to un-clarified molasses diluted with water. Therefore, supplementation of CSL to molasses is a viable option for improving biomass yield of baker's yeast.

\section{Biomass production studies at optimized conditions}

Biomass production was carried out in $5 \mathrm{~L}$ capacity fermenter by using molasses (unclarified) with an organic supplementation of corn steep liquor at the rate of $50 \mathrm{~g} / \mathrm{L}$ at optimum $\mathrm{pH}$ (6.0) and at an optimum incubation temperature $\left(30^{\circ} \mathrm{C}\right)$ and $120 \mathrm{RPM}$.

During the biomass production, a $\mathrm{pH}$ profile, reducing sugar content and biomass yield profile was also studied both in molasses + water and molasses + CSL medium. The results are depicted in table 17 and 18 respectively (Table 2; Figs. 11 and 12). 
Fig.1-6 Effect of different parameters on the biomass growth of Allinson yeast and FJ1 isolate
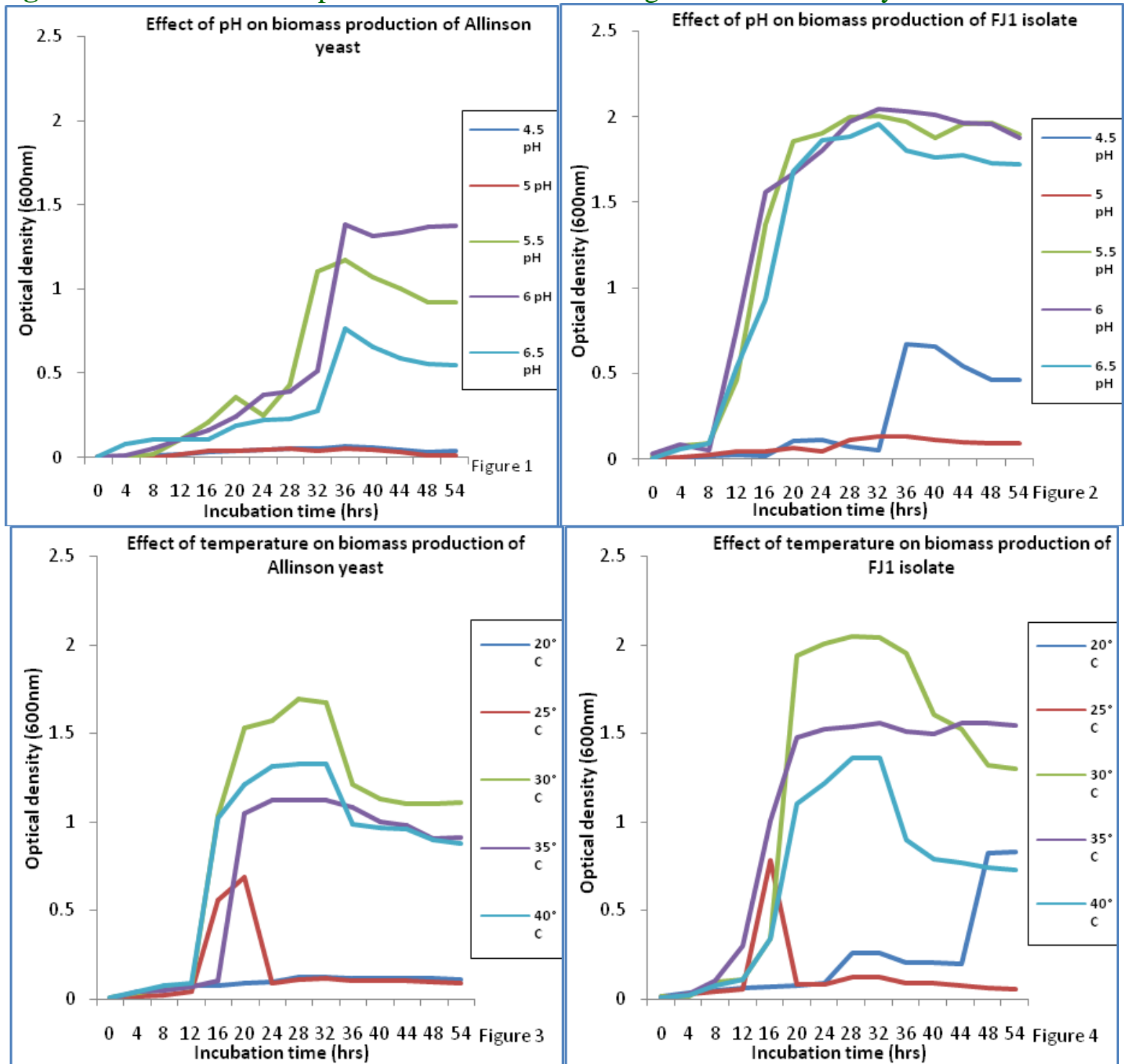

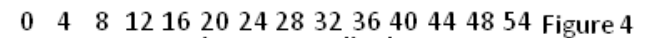
Incubation time (hrs)

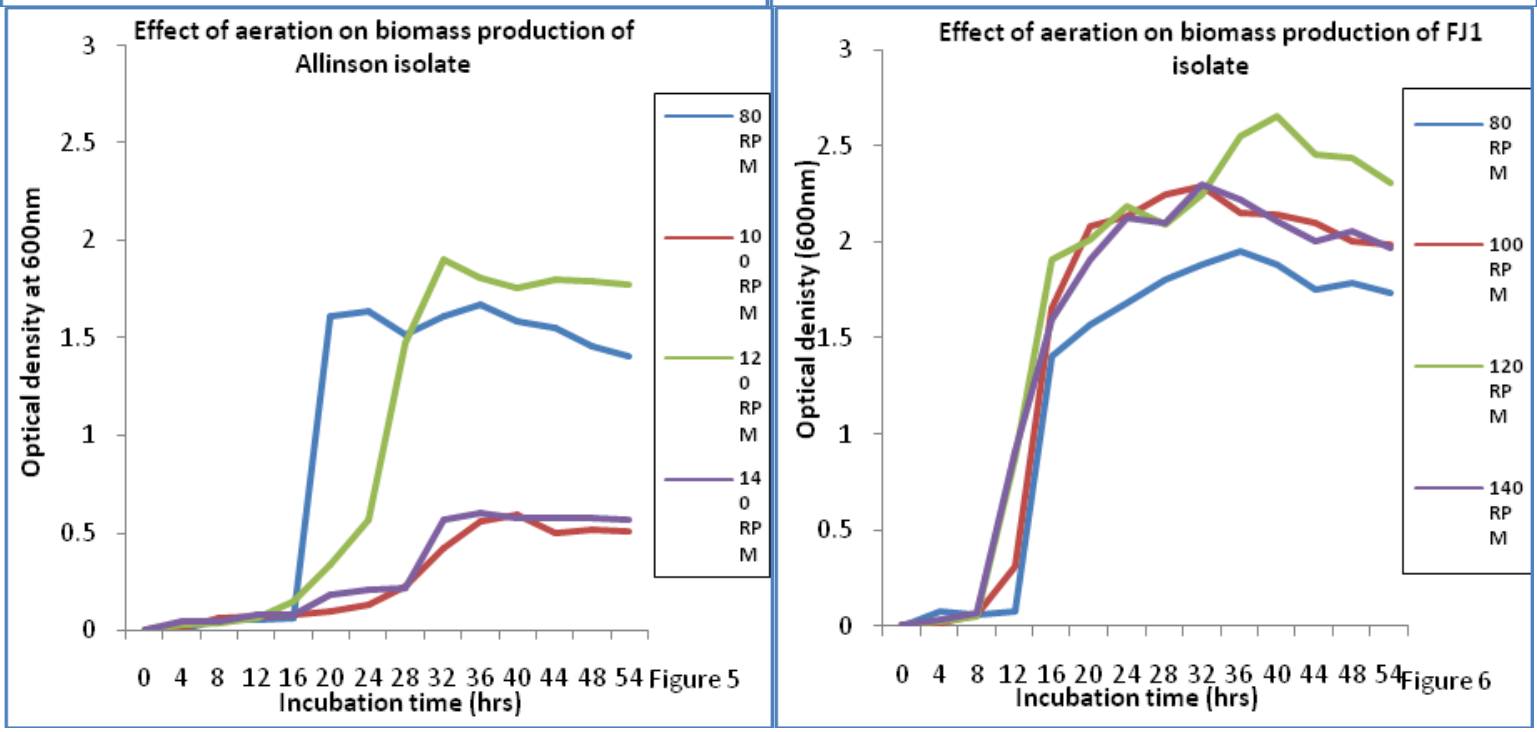


Fig.7 Effect of different agro-industrial wastes on biomass production of AllinsonYeast

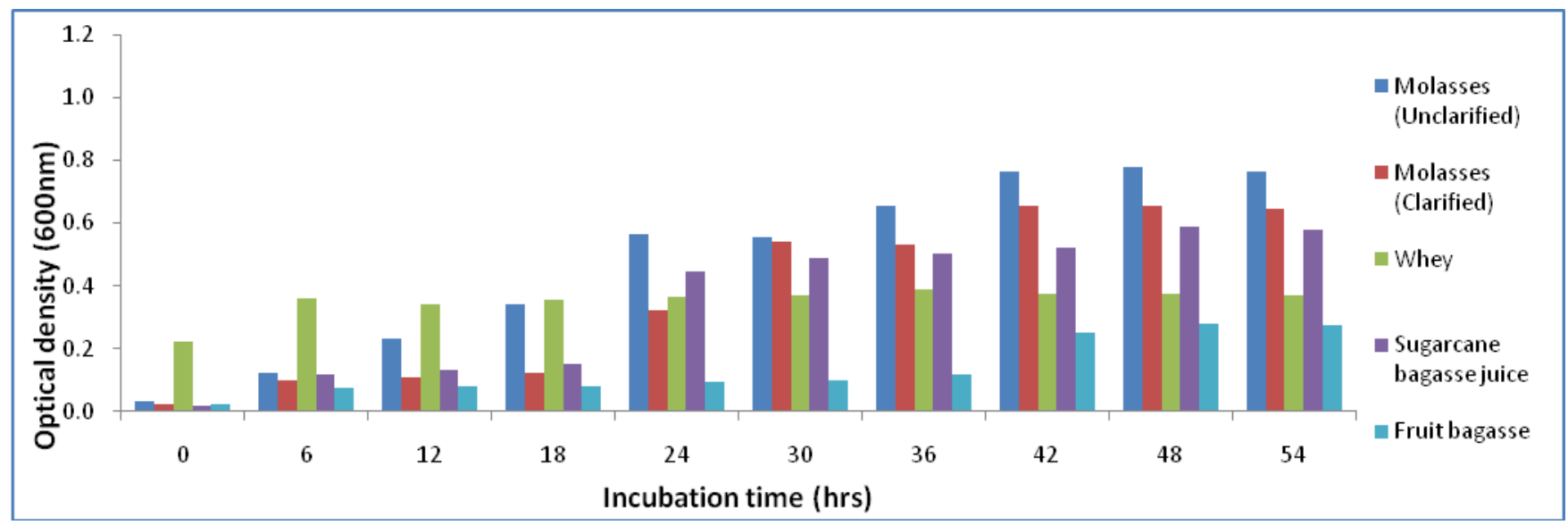

Fig.8 Effect of different agro-industrial wastes on biomass production of FJ1 Yeast

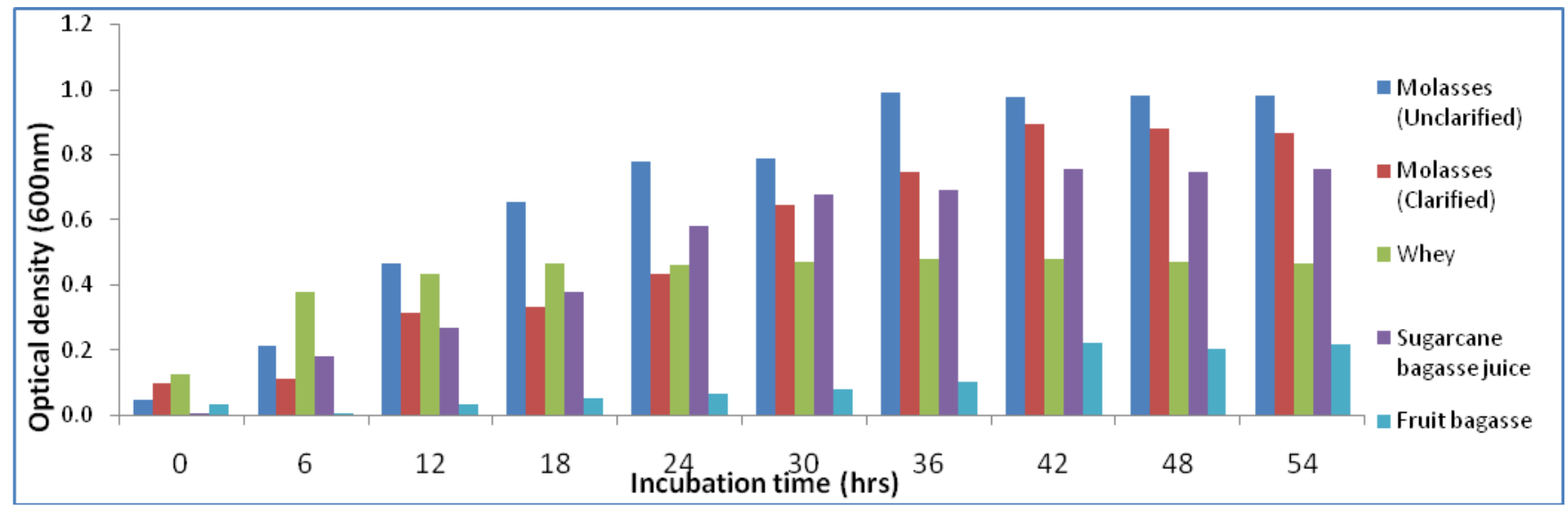

Fig.9 Effect of organic supplementation on biomass production of Allinson Yeast
Fig.10 Effect of organic supplementation on biomass production of FJ1 Yeast

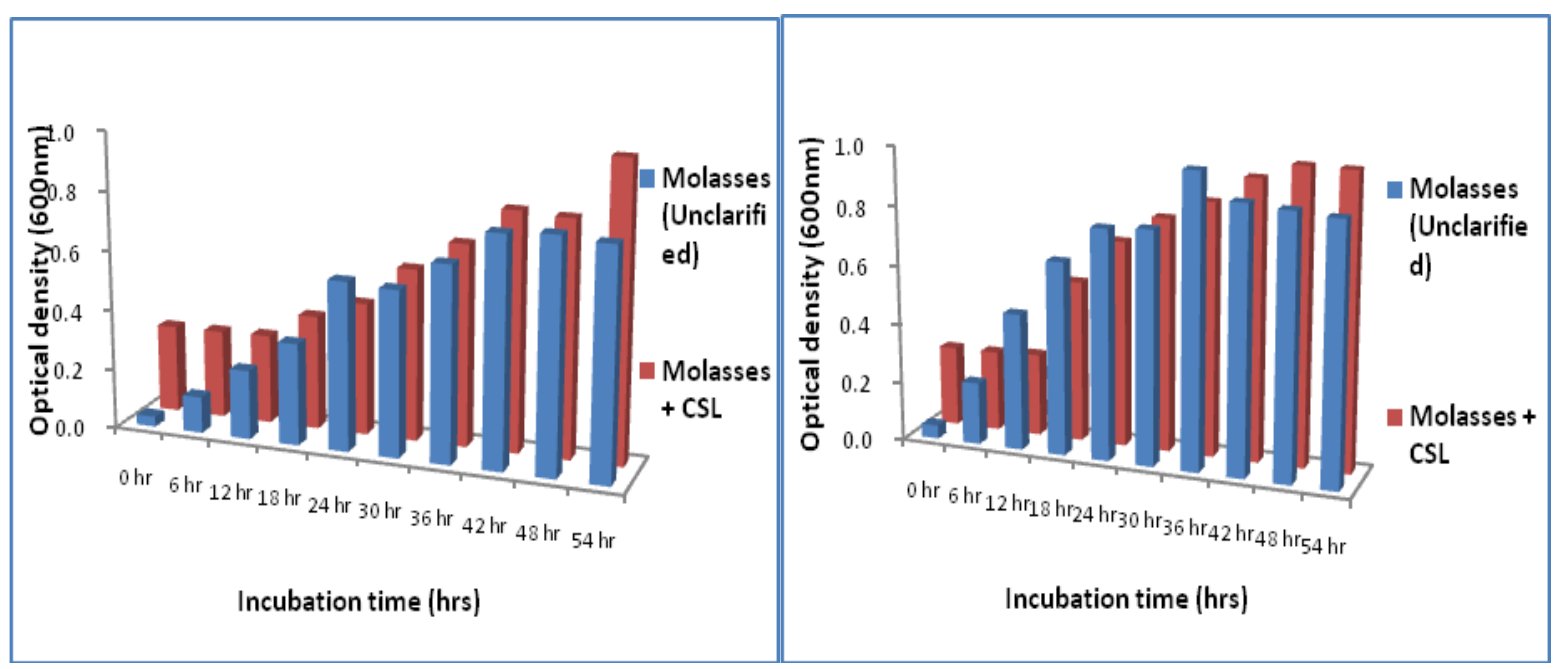


Fig.11 Biomass yield of Allinson yeast at optimized conditions
Fig.12 Biomass yield of FJ1 at optimized conditions

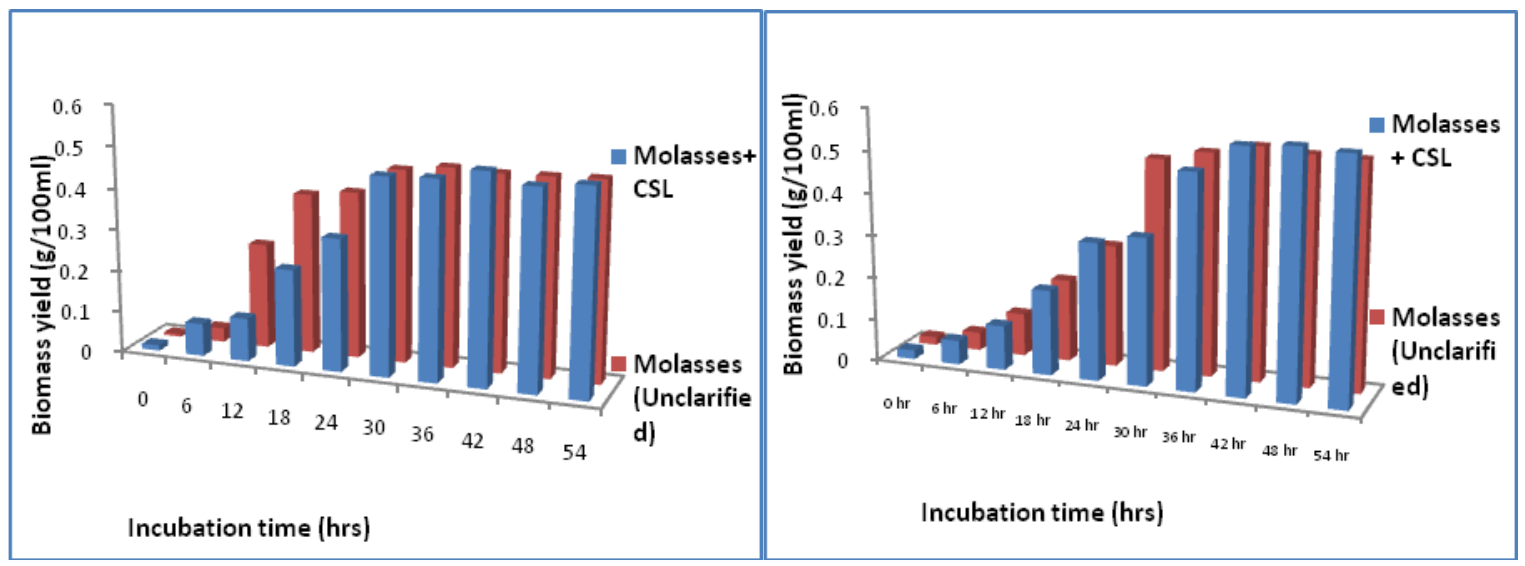

Fig.13 pH profile of supplemented and unsupplemented molasses during growth of FJ1 isolate

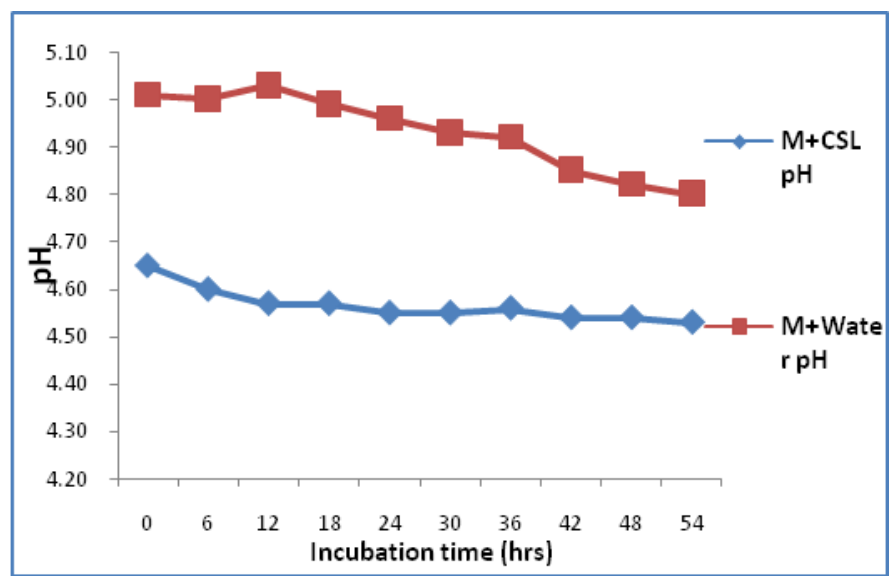

Fig.14 Reducing sugar content profile of growth of FJ1 supplemented and isolate unsupplemented molasses during growth of FJ1 isolate

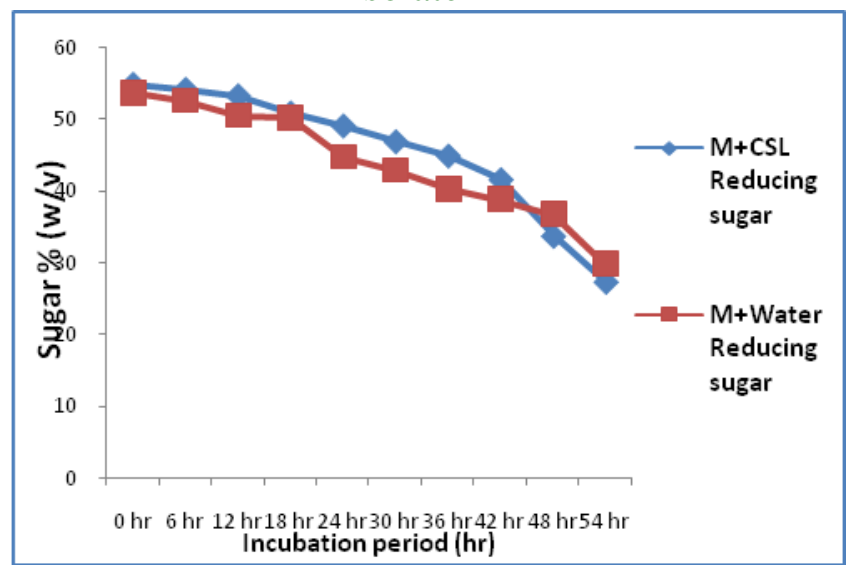

Fig.15 Biomass yield of supplemented and un-supplemented

Molasses during growth of FJ1 isolate

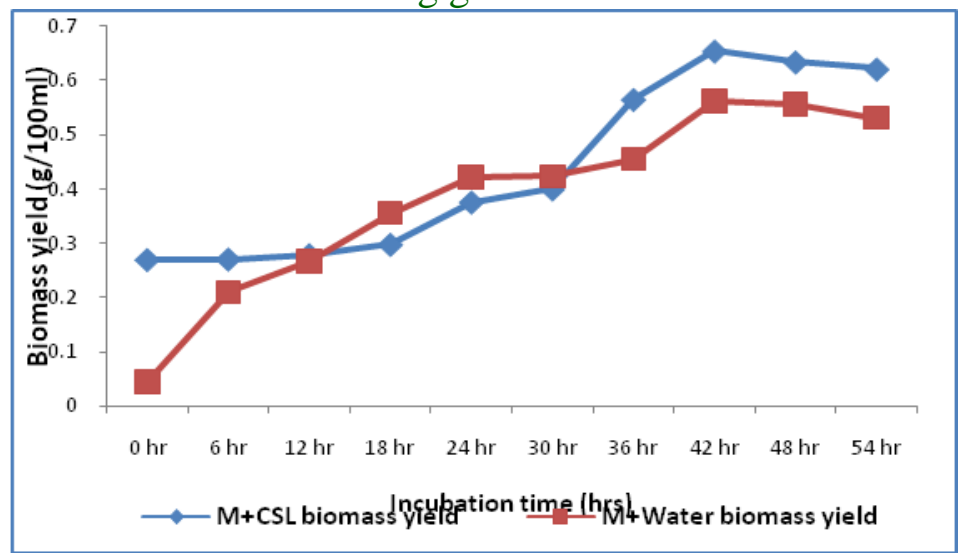


Table.1 Comparative amount of different constituents in agro-industrial wastes

\begin{tabular}{|c|c|c|c|c|c|}
\hline \multicolumn{5}{|c|}{ Carbon source } \\
\hline Components & $\begin{array}{c}\text { Molasses } \\
\text { (Clarified) }\end{array}$ & $\begin{array}{c}\text { Molasses } \\
\text { (Unclarified) }\end{array}$ & Whey & $\begin{array}{c}\text { Sugarcane } \\
\text { bagasse juice }\end{array}$ & $\begin{array}{c}\text { Fruit bagasse } \\
\text { juice }\end{array}$ \\
\hline $\begin{array}{c}\text { Crude Protein } \\
\text { content (\%) }\end{array}$ & 2.23 & 2.17 & 0.90 & 11 & 0.36 \\
\hline $\begin{array}{c}\text { Reducing sugar } \\
\text { \% (w/v) }\end{array}$ & 53.6 & 54.9 & 5.14 & 16.2 & 4.56 \\
\hline $\mathbf{p H}$ & 5.01 & 5.7 & 4.86 & 7.0 & 8.0 \\
\hline Brix $\left({ }^{\circ} \mathbf{B}\right)$ & 76.78 & 95.50 & 4.3 & 6.7 & 1.5 \\
\hline
\end{tabular}

Table.2 Comparative $\mathrm{pH}$ profile, reducing sugar and biomass yield of Molasses + water and molasses + CSL

\begin{tabular}{|c|c|c|c|c|c|c|}
\hline \multirow{2}{*}{$\begin{array}{c}\text { Medium } \\
\begin{array}{c}\text { Incubation } \\
\text { period }\end{array} \\
\end{array}$} & \multicolumn{3}{|c|}{ Molasses + Water } & \multicolumn{3}{|c|}{ Molasses + CSL } \\
\hline & pH & $\begin{array}{c}\text { Reducing } \\
\text { Sugar \% (w/v) } \\
\end{array}$ & $\begin{array}{c}\text { Biomass yield } \\
(\mathrm{g} / 100 \mathrm{ml})\end{array}$ & pH & $\begin{array}{c}\text { Reducing } \\
\text { Sugar (\%) } \\
\text { (w/v) }\end{array}$ & $\begin{array}{c}\text { Biomass yield } \\
(\mathrm{g} / 100 \mathrm{ml})\end{array}$ \\
\hline o hr & $5.01 \pm 0.09$ & $53.6 \pm 1.9$ & $0.45 \pm 0.013$ & $4.65 \pm 0.09$ & $54.9 \pm 2.06$ & $0.270 \pm 0.015$ \\
\hline $6 \mathrm{hr}$ & $5.00 \pm 0.09$ & $52.5 \pm 1.6$ & $0.211 \pm 0.013$ & $4.60 \pm 0.09$ & $54.2 \pm 1.79$ & $0.271 \pm 0.015$ \\
\hline $12 \mathrm{hr}$ & $5.03 \pm 0.09$ & $50.4 \pm 1.2$ & $0.267 \pm 0.013$ & $4.57 \pm 0.09$ & $53.3 \pm 1.33$ & $0.279 \pm 0.016$ \\
\hline $18 \mathrm{hr}$ & $4.99 \pm 0.09$ & $50.1 \pm 1.1$ & $0.356 \pm 0.014$ & $4.57 \pm 0.09$ & $50.9 \pm 1.30$ & $0.298 \pm 0.016$ \\
\hline $24 \mathrm{hr}$ & $4.96 \pm 0.09$ & $44.7 \pm 1.0$ & $0.422 \pm 0.012$ & $4.55 \pm 0.09$ & $49.1 \pm 1.11$ & $0.376 \pm 0.017$ \\
\hline $30 \mathrm{hr}$ & $4.93 \pm 0.09$ & $42.8 \pm 0.9$ & $0.424 \pm 0.008$ & $4.55 \pm 0.09$ & $46.9 \pm 1.06$ & $0.400 \pm 0.018$ \\
\hline $36 \mathrm{hr}$ & $4.92 \pm 0.09$ & $40.2 \pm 0.9$ & $0.456 \pm 0.17$ & $4.56 \pm 0.09$ & $44.9 \pm 1.02$ & $0.565 \pm 0.016$ \\
\hline $42 \mathrm{hr}$ & $4.85 \pm 0.09$ & $38.7 \pm 0.9$ & $0.563 \pm 0.017$ & $4.54 \pm 0.09$ & $41.6 \pm 0.99$ & $0.654 \pm 0.018$ \\
\hline $48 \mathrm{hr}$ & $4.82 \pm 0.09$ & $36.7 \pm 0.9$ & $0.556 \pm 0.018$ & $4.54 \pm 0.09$ & $33.7 \pm 0.97$ & $0.634 \pm 0.018$ \\
\hline $54 \mathrm{hr}$ & $4.80 \pm 0.09$ & $29.7 \pm 0.9$ & $0.532 \pm 0.018$ & $4.53 \pm 0.09$ & $27.3 \pm 0.90$ & $0.621 \pm 0.18$ \\
\hline CD (5\%) & NS & 3.99 & 0.452 & NS & 3.96 & 0.393 \\
\hline
\end{tabular}

Mean values \pm Standard Error of three independent experiments

Table.3 Proximate composition of raw material (Flour) and final product (bread)

\begin{tabular}{|c|c|c|c|c|}
\hline \multicolumn{2}{|c|}{ Components } & \multirow{3}{*}{$\frac{\text { Flour }}{\text { Amount }(\mathrm{g} / \mathbf{1 0 0 g})}$} & \multicolumn{2}{|c|}{ Bread } \\
\hline & & & Control $^{1}$ & Sample $^{2}$ \\
\hline & & & \multicolumn{2}{|c|}{ Amount (g/100g) } \\
\hline \multicolumn{2}{|c|}{ Fat } & $0.98 \pm 0.019$ & $3.43 \pm 0.07$ & $3.36 \pm 0.06$ \\
\hline \multicolumn{2}{|c|}{ Fibre } & $1.18 \pm 0.02300$ & $0.93 \pm 0.02$ & $0.98 \pm 0.02$ \\
\hline \multicolumn{2}{|c|}{ Protein } & $12.31 \pm 0.235$ & $14.9 \pm 0.28$ & $12.8 \pm 0.24$ \\
\hline \multicolumn{2}{|c|}{ Ash } & $0.63 \pm 0.012$ & $0.65 \pm 0.01$ & $0.67 \pm 0.01$ \\
\hline \multicolumn{2}{|c|}{ Moisture } & $12.515 \pm 0.238$ & $32.46 \pm 0.61$ & $36.31 \pm 0.69$ \\
\hline \multicolumn{2}{|c|}{ Carbohydrate } & $72.39 \pm 1.176$ & $47.63 \pm 0.91$ & $45.88 \pm 0.87$ \\
\hline \multirow[t]{2}{*}{ Gluten (\%) } & Wet & $30.955 \pm 0.59$ & ND & ND \\
\hline & Dry & $10.175 \pm 0.194$ & ND & ND \\
\hline
\end{tabular}

* Mean values \pm Standard Error of three independent experiments

${ }^{1}$ Bread prepared from commercial yeast (Allinson)

${ }^{2}$ Bread prepared from FJ1 isolate. 
Table.4 Comparative physico- chemical analysis of final product made from Commercial yeast and FJ1

\begin{tabular}{|l|c|c|c|c|c|c|c|}
\hline \multirow{2}{*}{ Parameters } & \multirow{2}{*}{$\begin{array}{c}\text { Loaf weight } \\
(\mathbf{g})\end{array}$} & \multirow{2}{*}{$\begin{array}{c}\text { Loaf volume } \\
(\mathbf{c c})\end{array}$} & \multicolumn{2}{|c|}{ Crumb characteristics } & \multicolumn{2}{c|}{ Crust characteristics } \\
\cline { 4 - 8 } & & Colour & Texture & Grain & Colour & Shredness \\
\hline Control $^{\mathbf{1}}$ & $145.65 \pm 1.85$ & $480 \pm 2.89$ & CW & Soft & Fine & LB & NS \\
\hline Sample $^{\mathbf{2}}$ & $136.59 \pm 1.73$ & $380 \pm 1.15$ & $\mathrm{C}$ & Soft & Fine & LB & NS \\
\hline
\end{tabular}

${ }^{1}$ Control- Bread prepared from commercial yeast (Allinson)

${ }^{2}$ Sample- Bread prepared from FJ1 isolate.

CW- creamish white C- Creamish LB- Light Brown NS- No shredding

* Mean values \pm Standard Error of three independent experiments

Table.5 Sensory evaluation of bread prepared from commercial yeast and FJ1 isolate

\begin{tabular}{|l|c|c|c|c|c|}
\hline Sensory attributes & Appearance & Colour & Texture & Flavour & Overall acceptability \\
\hline Control & $8.25 \pm 0.29$ & $8.12 \pm 0.14$ & $8.0 \pm 0$ & $7.87 \pm 0.36$ & $8.13 \pm 0.14$ \\
\hline Sample & $7.63 \pm 0.43$ & $7.75 \pm 0.29$ & $7.75 \pm 0.29$ & $7.75 \pm 0.29$ & $7.72 \pm 0.29$ \\
\hline
\end{tabular}

9- Liked extremely

8- Liked very much

7- Liked moderately

* Mean values \pm Standard Error of three independent experiments
6- Liked slightly 3-Disliked moderately

5- Neither liked nor disliked 2- Disliked very much

4- Disliked slightly 1- Disliked extremely

\section{A. Control (Commercial yeast) B. Sample (FJ1 isolate)}
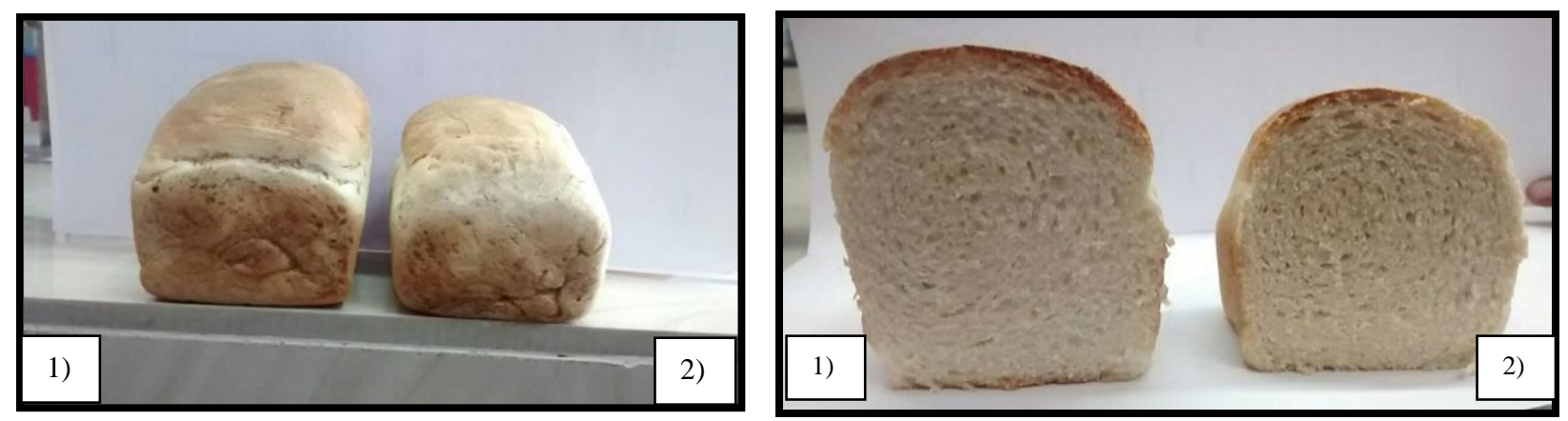

\section{A. Control (Commercial yeast) B. Sample (FJ1 isolate)}

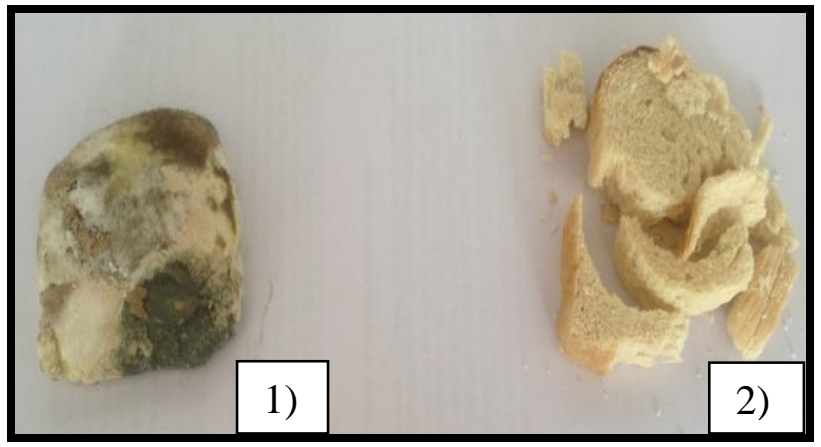


The yeast biomass generated by batch fermentation was separated by centrifugation after $48 \mathrm{hr}$ of growth. The supernatant was cleared by washing several times with distilled water and further centrifugation at 6000 RPM for 10 mins was done. The obtained pellet was further used in the breadmaking process.

A study[3], which suggested that at $18 \%$ sugar molasses medium, brand A recorded maximum yield $(5.425 \mathrm{~g} / \mathrm{L})$, while at $6 \%$ sugar concentration brand $\mathrm{G}$ recorded the highest yield of $4.15 \mathrm{~g} / \mathrm{L}$. No significant difference was observed between the different strains at 2,10 or $14 \%$ sugar molasses concentration.

Comparative change in $\mathrm{pH}$, reducing sugar and biomass yield was also observed in both the medium, with supplementation of corn steep liquor as well as molasses with water dilution. No significant difference was observed in the $\mathrm{pH}$ with time, whereas reducing sugar content decreased from $53.6 \pm 1.9$ to $29.7 \pm 0.9 \%$ (w/v) within $54 \mathrm{hr}$ of incubation in molasses + water and from $54.9 \pm 2.06$ to $27.3 \pm 0.9 \%(\mathrm{w} / \mathrm{v})$ in molasses + CSL (Figs. 13 and 14).

Results showed a maximum biomass yield of $6.54 \mathrm{~g} / \mathrm{L}$ by $\mathrm{FJ} 1$ isolate. In comparison to it, molasses medium without supplementation showed a biomass yield of $5.63 \mathrm{~g} / \mathrm{L}$ of the FJ1 isolate. Therefore, the efficiency of using organic supplementation instead of inorganic supplementation was computed to be $16.16 \%$ in case of the FJ1 isolate. This also portrays the applicability of using organic wastes, which are more cost-effective, and do not pose any chemical change to the solution into the medium for biomass production. Since the biomass yield of molasses supplementation with corn steep liquor was greater as compared to molasses un-clarified, it was chosen as the best suited agro-industrial waste for biomass production. Hence, biomass yield on this medium was used for the bread preparation after sufficient biomass yield. Since the biomass yield of molasses supplementation with corn steep liquor was greater as compared to molasses un-clarified, it was chosen as the best suited agro-industrial waste for biomass production. Hence, biomass yield on this medium was used for the bread preparation after sufficient biomass yield (Fig. 15).

\section{Physicochemical properties of raw materials and final product}

Standard protocols of AACC 2000 were used to determine the proximate composition of raw material including fat, fibre, protein, ash, moisture, carbohydrate and gluten and the results are given in table 3 .

\section{Baking properties}

\section{Quality analysis of final product}

Significantly higher loaf weight was observed in bread prepared from commercial yeast $(145.65 \pm 1.85 \mathrm{~g})$ as compared to the bread prepared from a FJ1 isolate $(136.59 \pm 1.73 \mathrm{~g})$. Similar to the loaf weight, a significant difference was observed in loaf volume, where the bread prepared from commercial yeast had a volume of $480 \pm 2.89$ cc while bread prepared from $\mathrm{FJ} 1$ isolate revealed a volume of $380 \pm 1.15 \mathrm{cc}$ (Table 4).

This difference in bread quality can be attributed to the different leavening ability of the yeasts.

Further, bread from commercial yeast showed creamish white colouration while FJ1 isolate showed creamish. No significant difference was observed in the case of crumb characteristics including soft texture, fine grain and crust characteristics, including light brown color and no shredding. 
Evaluation of sensory attributes of bread prepared from commercial yeast and FJ1

Sensory changes in food products resulting from intentional and unintentional interactions with the raw materials used, and any other significant chemical and physical changes governing the product. Sensory perceiveness with regard to appearance, color, texture, flavor and the overall acceptability was carried out and the data was analyzed.

Sensory evaluation of data of the bread prepared from commercial yeast and FJ1 isolate (Table 5) revealed that the bread prepared from commercial yeast had a higher score for all sensory attributes than the bread prepared from FJ1. Non- significant variations were observed with respect to the sensory score of all the attributes. The mean acceptability score for bread prepared from commercial yeast was 8.13 while that for bread prepared from FJ1 was 7.72. The reason for the decrease in acceptability score was the differential dough leavening ability of commercial yeast in comparison to the FJ1 isolate.

\section{Shelf stability of bread fermented by selected commercial yeast and $\mathrm{FJ} 1$ isolate}

Shelf stability of the final product was studied out for a period of 1 month at an incubation temperature of $25^{\circ} \mathrm{C}$. Periodic observation of bread prepared from commercial yeast and FJ1 isolate revealed the better shelf stability of the bread prepared from FJ1 isolate in comparison to that prepared from commercial yeast.

Since Allinson and FJ1 isolate were considered best based on their earlier studies related to biochemical, physic-chemical and various other properties, biomass yield efficiency was checked on various parameters which included $\mathrm{pH}$, temperature, aeration, carbon and nitrogen source. Unclarified molasses with organic supplementation with corn steep liquor was considered best in terms of biomass yield among all the carbon sources used. Moreover, the efficiency of production in case of Allinson yeast was found to be $16.02 \%$ while it was $15.34 \%$ in case of FJ1 isolate after the addition of organic supplementation of CSL @ 50g/L. Therefore, mass cultivation was done which was further used in the preparation of a final product. Bread was prepared from the yeasts and was further evaluated based on certain parameters by a panel of judges which predicted a considerable difference among the two yeasts. Allinson yeast showed characters on a higher side whereas, in terms of shelf stability of the bread, FJ1 showed a better response. It showed better shelf stability after 1 month of incubation at room temperature while spoilage of the bread produced by Allinson yeast was observed.

Therefore, this research concluded comparable bread production by both the commercial as well as the lab isolate. Whereas better shelf life stability by the bread produced from the lab isolate was observed.

\section{References}

Prescott M L, Harley J P, Klein D A (2008) Microbiology (7th Edition).McGraw Hill Publishers, New York, pp. 207210.

Almeida M J, Pais C S (1996) Characterization of the yeast population from traditional corn and rye bread doughs. Lett Appl Microbiol 23: 15458.

Nasr N F, Zaky A S (2011) Five factors affecting the production of baker's yeast using sugarcane molasses. International food congress- Novel approaches in food industry Pp 1051-056.

John R P, Nampoothiri K M, Pandey A 
(2007) Fermentative production of lactic acid from biomass: an overview on process developments and future perspectives. Appl.microbial.biotechnol 74(3): 524-534.

Malik H (2016) Utilization of agro-industrial wastes for the biomass production of baker's yeast. M.Sc. Thesis, Punjab Agricultural University, Punjab.

Grba S, Stehlik-Tomas V, Stanzer D, Vahèiæ N, Škrlin A(2002) Selection of yeast strain Kluyveromyces marxianus for alcohol and biomass production on Whey. ChemBiochemEngQ16 (1): 1316.

Rodriguez-Vazquez R, Villanueva-Ventura G, Rios-Leal E (1992) Sugarcane bagasse pith dry pretreatment for single cell protein production. Bioresource Technol 39: 17-22.

Stabnikova O, Jing-Yuan W, Ding H B, JooHwa $T$ (2005) Biotransformation of vegetable and fruit processing wastes into yeast biomass enriched with selenium. Bioresource Technol 96: 74751.

AACC (2000) Approved Methods of American Association of Cereal Chemists. (10 ${ }^{\text {th }}$ ed.) the Association St. Paul, MN.

Irvine $\mathrm{G} \mathrm{N}$, McMullan M E (1960) the 'Remix'baking test. Cereal Chem 37(1):
63.

Nagi H P S, Sharma S, Sekhon K S (2007) Handbook of cereal Technology - A practical approach. Pp. 78-79. Kalyani Publishers, New Delhi.

Haq I, Ali S (2005) Invertase production from a hyperproducing Saccharomyces cervisiae strain isolated from dates. Pakistan J Bot 37(3): 749-59.

Win S S, Impoolsup A, Noomhorm A (1996) Growth kinetics of Saccharomyces cerevisiae in batch and fedbatch cultivation using sugarcane molasses and glucose syrup from cassava starch. J IndMicrobiol 16(2): 117-123.

Oura E (1974) Effect of aeration intensity on the biochemical composition of Baker's Yeast. I. Factors Affecting the Type of Metabolism. Biotechnol Bioeng 16: 1197-212.

Elena P, Rapeanu G, Bonciu C, Hopulele T (2009) the annals of the university dunarea de jos of galati fascicle VI Food technology, New Series Year III. Paper presented at the International Symposium Euro - ailment- Romania Pp 49-56.

Damtew (2008) Studies on the development of baker's yeast using cane molasses. M.Sc. Thesis, School of Graduate Studies, Addis Ababa Univ., Ethopia.

\section{How to cite this article:}

Hiranmay Malik, Priya Katyal and Savita Sharma. 2017. Biomass Yield Efficiency of Baker's Yeast Strain on Agro-Industrial Wastes and Its Utilization in Bread Making. Int.J.Curr.Microbiol.App.Sci. 6(8): 2740-2753. doi: https://doi.org/10.20546/ijcmas.2017.608.328 